\title{
ICOLD - sustainable design and post-closure performance of tailings dams
}

\author{
A.G. Bjelkevik Sweco Infrastructure AB, Sweden
}

\begin{abstract}
The International Commission on Large Dams (ICOLD) is a non-governmental international organisation that was established in 1928 as a forum for the exchange of knowledge and experience in dam engineering. This organisation is made up of various subcommittees, one of which is the Committee on Tailings Dams and Waste Lagoons. Formed in 1928, this sub-committee has produced a number of bulletins related to tailings dam design. The next bulletin, "Sustainable Design and Post-Closure Performance of Tailings Dams", will be published in 2011/12 for tailings dam designers intending to achieve sustainable development.
\end{abstract}

Sustainable development in this paper is defined according to the Bruntland Report (UNWCED, 1987): "development that meets the needs of the present without compromising the ability of future generations to meet their own needs". This means that mining projects, including tailings management facilities (TMFs), should be financially viable, technically appropriate, environmentally sound and socially responsible (ICMM, 2008). In order to fulfil that brief, closure of TMFs need to be managed carefully. This new ICOLD Bulletin is intended to be a guide in this process.

The Bulletin is compiled into three major sections, with in-depth discussion on the following:

- Sustainable closure principles, covering closure objectives, closure design life, the influence of deposition methods, financial principles, regulations and risk management principles.

- Sustainable design considerations, covering consequence classification at closure, long term physical stability, ecological and social stability.

- Long-term monitoring: covering instrumentation and control after remediation has taken place.

This paper sets out some of the guiding principles and details that will be contained in the new ICOLD bulletin.

\section{Introduction}

The International Commission on Large Dams (ICOLD) is a non-governmental international organisation that provides a forum for the exchange of knowledge and experience in dam engineering. The organisation leads the profession in ensuring that dams are built safely, efficiently, economically, and without detrimental effects on the environment. Its original aim was to encourage advances in the planning, design, construction, operation, and maintenance of large dams and their associated civil works, by collecting and disseminating relevant information and by studying related technical questions. Since the late 1960s, focus was put on subjects of current concern such as dam safety, monitoring of performance, re-analysis of older dams and spillways, effects of ageing and environmental impact. More recently, new subjects include cost studies at the planning and construction stages, harnessing international rivers, information for the public at large, and financing.

ICOLD is directed by the annual executive meeting consisting of representatives from all the Member Countries and of the Officers of the Commission. Any independent country can become a "Member Country" and constitute a National Committee consisting of persons competent in the matters relating to dams. The ICOLD Executive, comprising the President, Secretary General and six elected Vice-Presidents, are responsible for process formalisation at the annual executive meeting, as well as the resolution of all questions concerning organisation, direction of studies, investigations and experiments, administration of all funds and properties, operation of the central office and any other relevant business of the Commission. The Executive approves the budget, appoints and organises all Committees, and elects new Member Countries. 
ICOLD consists of 92 National Committees with approximately 10,000 individual members. ICOLD members are essentially practising engineers, geologists and scientists from governmental and private organisations, consulting firms, universities, laboratories and construction companies.

The organisation works through various sub-committees, currently 28 of them, of which one is the Committee on Tailings Dams and Waste Lagoons. This "tailings committee", consisting of 18 members (see Acknowledgement), has since 1976 produced a number of bulletins related to tailings dam design. The latest bulletin, Sustainable Design and Post-Closure Performance of Tailings Dams (The ICOLD Bulletin), discussed in this paper and to be published in 2011/12, is presented for tailings dam designers intending to achieve sustainable development as a response to the global need for increased focus on this important development aspect, which possibly has not been fully understood or adequately taken into account in the past.

The bulletin is compiled into three major sections, with in-depth discussion against each topic, namely:

- Sustainable closure principles.

- Sustainable design considerations.

- Long-term monitoring.

This paper summarises some of the guiding principle, considerations and details that are contained in the new (unpublished) ICOLD bulletin.

\section{Methodology}

ICOLD bulletins are produced by compilation of knowledge and information gathered from the members of the committee and their respective national committees. Each member of the committee/national committee decides how much they want to participate in the process and influence the outcome. As all work is voluntary it is sometimes difficult for individuals to find the time required, resulting in a slow publication process. The bulletin is, however, believed to summarise the international level of knowledge on the subject, in this case, Sustainable Design and Post-Closure Performance of Tailings Dams.

\section{Discussion}

\subsection{General}

It is generally recognised and accepted that tailings dams have the potential to impact significantly on the environment, public health, the local community and other potentially affected parties as well as a mine's economic stability. Over the last 30 years significant improvements have been made in the design and operation of tailings dams with the objective of increasing safety and minimising the impact on the environment, both during operation and after closure. Therefore, enduring value, encompassing established sustainable development principles, is the key to the social licence to develop, operate and close a mine and its associated infrastructure, including its tailings dams. A tailings dam, comprising the dam and the impoundment, with assured sustainable long-term physical, chemical, environmental and social stability requires specific and detailed consideration over time with frequent reviews during the planning, design, operation, closure and post-closure phases of its long-term existence.

The ICOLD bulletin serves to set out the specific requirements and objectives for sustainable closure of a tailings dam through good stewardship and cost-effective solutions. Sustainable development in this case is defined, according to the Bruntland Report (UNWCED, 1987) as the "development that meets the needs of the present without compromising the ability of future generations to meet their own needs". In the new ICOLD bulletin sustainable development is defined as "sustainable development is not a fixed state of harmony, but rather a process of change in which the exploitation of resources, the direction of investments, the orientation of technological development, and institutional change are made consistent with future as well as present needs." This means that the entire mining project, including consideration of their tailings dams, should be financially profitable, technically appropriate, environmentally sound and socially responsible (ICMM, 2008). In order to fulfil that brief, closure of tailings dams need to be managed carefully. 
The International Institute for Sustainable Development (IISD, 2002), address the sustainability issue in the form of seven questions, which are repeated below in order to establish the context of the term "sustainability" for an industrial or mining project, including associated tailings dams.

1. Engagement: Are engagement processes (with all affected communities of interest) in place and working effectively?

2. People: Will people's well-being be maintained or improved during and after the project or operation?

3. Environment: Will the integrity of the environment be taken care of in the long-term?

4. Economy: Is the economic viability of the company assured; is the community and regional economy better off, not only during operation but into post-closure?

5. Traditional and non-market activities: Is the viability of traditional and non-market activities in the community and surrounding area maintained or improved with the project or operation?

6. Institutional and governance: Are the rules, incentives and capacities in place now and as long as required to address project or operational consequences?

7. Synthesis and continuous learning: Does a synthesis show the project to be net positive or negative for people and ecosystems? Is the system in place to repeat the assessment from time to time?

\subsection{Sustainable closure principles}

It is generally accepted that a tailings dam is an integral part of the mine development plan and that it should be designed for closure from the project initiation stage. The closure plan should be revised at regular intervals to ensure that it remains appropriate and that the cost is covered by financial guarantees. The following specific principles apply to the successful achievement of sustainable design and post closure performance:

- The main objective of mine closure should be the long-term stabilisation of physical, chemical, ecological and social conditions of the tailings dam to prevent ongoing degradation.

- Long-term water quality issues must be monitored on an ongoing basis where reactive residual tailings may generate poor quality leachates.

- The focus of long-term planning should be pollution prevention, minimisation of adverse impacts and a site-specific approach for each facility.

- The regional context should be considered, specifically the potential impact on adjacent properties.

- The closure plan should also address health, safety and employment impacts on local communities.

- The expectations and concerns of all interested and affected parties must be addressed and incorporated into the closure plan.

- A full risk assessment should be undertaken during the closure concept design phase of the tailings dam.

International practice has been set by a number of organisations, such as the World Bank, the International Council on Mining and Metals (ICMM), the European Union (EU), different Government departments and national committees in various countries etc.

There is no current consensus about the length of time a closure design should target, i.e. consensus about closure design life. There is a general agreement that a tailings dam and its contents should be left in a condition which will permanently withstand natural forces and not cause ongoing harm to the environment. In many countries this comprises a design life of 1,000 years or more. In general the intent is to provide a long-term sustainable solution in which it is possible to leave the site in a condition which is self-sustaining and of benefit to the community without the need for ongoing maintenance and expenditure. The principal technical requirements are to ensure physical, chemical, ecological and social stability. The principal social 
requirements are to ensure human health and safety and to leave the facility with appropriate and sustainable land and water use that meets the community objectives.

It is important to estimate the cost of closure at the earliest possible stage in the project as it can influence the feasibility study in determining the financial viability of the project or even the minimum grade of ore that will be mined. Early estimates rely on a number of assumptions and ongoing work and should therefore focus on those assumptions with the potential to have a major impact on the estimates. The financial model should involve the following components related to closure, taking into account relevant regulations:

- Estimates of closure costs.

- Whether there will be stages where closure of certain storage facilities or treatments of final slopes will be carried out progressively.

- Ongoing monitoring and management costs.

- Method of providing funds for closure.

- Variation in cost of financing over time.

- Allowance for risk contingency.

Risk is defined as the product of likelihood (probability of occurrence) times the consequence of the occurrence. The main objective of a sustainable closure of a tailings dam is to reduce the risks associated with the closure to an acceptable minimum.

\subsection{Sustainable design considerations}

\subsubsection{General}

There are current ICOLD bulletins and many other excellent publications that provide guidelines for the conventional design of tailings dams and it is not the intention of The ICOLD bulletin to repeat these, but rather to highlight the specific aspects that require special consideration when a sustainable design life of 1,000 years or more is adopted. It should also be noted that design and closure requirements may vary widely from case to case and from country to country. Designing for the sustainable long-term may, however, require an approach of increased conservatism, appropriate selection of deposition method and careful attention to failure consequences. In order to be conservative the precautionary principle is in most cases recommended.

In order to address sustainability it is necessary to consider the following impacts that the tailings dam may have in the long-term with regard to:

- Physical stability.

- Chemical stability.

- Ecological stability.

- Social stability in the area of influence (although this is difficult to forecast into the future).

It is also good to ask the following typical questions in order to achieve satisfactory conditions for sustainable closure at the conceptual and detail design stages:

- What will be the final form of the top and outer surfaces of the dam at the end of the active deposition phase? And how will the desired stable closure shape be achieved and maintained in the long-term?

- What will be the loading conditions at closure and in the long-term? Will these change with time?

- What factors can affect the long-term overall physical, chemical, ecological and social stability of the dam?

- How must the dam and associated structures be designed to ensure sustainable hydraulic stability of the tailings dam, particularly with regard to extreme events? Extreme events, in the time scale of 
long-term, are in most cases the maximum credible earthquake (MCE) and probable maximum flood (PMF).

- What possible factors will a hazard analysis for closure condition and long-term condition reveal? How must these be addressed at design stage?

Consequence classification is today often carried out during operation of tailings dams and surveillance is normally designed in recognition of the severity of the consequences should failure occur. The classification with regard to consequences needs to be carried out for the long-term and closure phase as well, due to different loading conditions during this long timeframe.

\subsubsection{Long-term physical stability}

It is essential to acknowledge that no form of long-term stable tailings dam, with regard to physical, chemical, social, ecological or otherwise stability, can be achieved unless the tailings deposit primarily remains stable and remains in place. The physical stability of a tailings dam must therefore be of first priority. When designing for long-term dam stability a number of conditions should be considered that may influence the material properties of the dam, foundation and tailings, or alter the performance of filters, drains, or liners. Additionally, cumulative effects of events (seismic and flood events) over the long-term should be considered. Conditions to consider are:

- Weathering and degradation of material properties (e.g. physical and chemical weathering).

- Stress and strain effects (e.g. consolidation which may lead to settlements, increase in strength and/or reduction in permeability).

- Internal and external erosion (e.g. material transport within the dam and erosion on the outer slopes of the dam and/or the surface of the impoundment. Mimicking nature may be considered in order to create natural landforms with a proven long-term stability, which may have a social/aesthetic acceptance as well).

- Temperature effects (e.g. freezing and thawing and changes of permafrost conditions).

- Degradation of functions and/or non-natural materials. For example the performance of drains, geosynthetics or other functions or materials in a long-term perspective is discouraged.

- Hydraulics; e.g. management of water within the dam wall (e.g. hydraulic gradients) and surface water (drainage and spillways), particular extreme events, climate change and man-made hazards.

- Long-term seismic effects need to consider a suitable design return period, the potential for cumulative events, the risk of liquefaction and it should be conservative.

- Geo and other hazards, like landslides, avalanches, debris flow, fauna, flora and humans (e.g. improper land use, excavation, removal of material etc.).

\subsubsection{Long-term chemical stability}

Long-term chemical effects include the potential transfer of contaminants of potential concern into the receiving environment via water, seepage, re-suspension, air, or biologically through plants via the sourcereceptor relationship. Acid rock drainage (ARD) and metal leaching (ML) can be significant issues.

\subsubsection{Long-term ecological stability}

The long-term ecology of the tailings dam, and its surroundings, needs to be consistent with the planned land use, and conversely, the planned land use needs to be consistent with the ecology in the region. To be able to develop a long-term, ecologically sustainable area, the surrounding environment and ecology (i.e. the existing ecosystem, must be interpreted with regard to climate, material properties, vegetation, animals, and humans) both on land and under water. The possible long-term changes to these aspects should also be considered and mitigated.

Careful planning and monitoring of the function of the tailings dam and the surrounding environment during operation is necessary in order to be able to finalise a sustainable closure plan. The closure plan must be 
updated on a regular basis in order to accommodate, or make allowance for, any changes in the local ecology and in order to recognise any new beneficial or negative impacts. Failure to modify the closure plan may lead to problems where the permitted closure does not allow for, or may be in direct conflict with, these changes.

\subsubsection{Long-term social stability}

Long-term social stability in the tailings dam vicinity is integral to physical, chemical and ecological stability. Social stability begins with the development of site-specific land and water use objectives that support long-term sustainable use of the tailings dam area. Examples of social sustainability could include:

- Use of tailings lakes as recreation lakes, for water supply or mini-hydro projects.

- Use of tailings surfaces for golf courses or playing fields.

- Use of tailings dams for habitat or ecological reserves.

A parallel objective with social stability is to reduce the risks associated with the physical, chemical and ecological stability to low levels. A benefit of this approach is that land and water use can then focus on optimising the use of the tailings dam to benefit society, and habitation in the closed tailings dam locality with negligible risk.

Long-term social sustainability requires that the financial support for any future maintenance or repair is available to the party taking over the responsibility. Long-term financial sustainability could also be supported with land or water use objectives that could generate income, such as power, recreation charges, land sales, etc.

\subsection{Long-term monitoring}

Long-term monitoring will be different depending on the purpose, i.e. depending on which phase the monitoring takes place, during the post closure or the long term phase. One other aspect is that an emergency plan should be developed not only for the operation phase, which is usual today at most sites, but also for closure and the long-term phase.

\subsubsection{Post closure}

The immediate period following closure of operations is referred to as the post closure period. During post closure there are the active and passive care phases. Monitoring objectives will be different for these two phases. During the active care phase, monitoring should be undertaken in order to demonstrate that the closure design fulfils the requirements of final closure, i.e. long-term sustainable compliance with regard to physical, chemical, ecological and social stability. During the passive care phase, limited monitoring is often still required in order to demonstrate that the final closure design fulfils the requirements over time.

\subsubsection{Long-term}

The objective over a long period of time, after post closure, is to be able to leave the tailings dam without active or ongoing monitoring. This is, however, not always possible, resulting in most tailings dams requiring some degree of long-term monitoring. Monitoring should, at this stage, be periodic and if possible, a system may be put in place that provides a warning should a high consequence event occur. Such a system, however, requires human intervention, resulting in the need for "some institution" to be responsible.

However, it must be stated that closure cannot be sustainable without sustainable institutions to implement it. It is inevitable that human intervention will be required in the long-term to ensure closure stability. Some form of control of the area should therefore be included in the long-term closure plan in order to at least prevent the site from human hazards (improper land use, excavation etc.). Governments undergo constant change and are not necessarily available for the long-term phase required. The World Bank, which is often considered as a primary authority on sustainability, is notably silent on this issue, stating only that the legal and regulatory framework for mine closure must be in place (World Bank and IFC, 2002). 


\section{Conclusions}

Designing for closure is important and needs to be addressed as early as possible. How to design sustainable closure for a tailings dam is a complex process and has to be addressed individually for each site. The ICOLD bulletin intends to raise the issue of sustainable closure and to highlight important issues and questions to consider. No answers can possibly be given on how to close a tailings dam as no one site is like another.

To achieve sustainable closure in the long-term planning must start as early as possible, preferably already at the time of initial planning for the mine/tailings dam. All parties affected need to be involved in the process and the closure plan needs to be updated on a continuous basis. The tailings dam, mine site and surroundings need to be monitored before, during and after mining operations in order to be able to adjust the closure plan.

Experience and knowledge is continuously gathered as more tailings dams are closed and time shows how well the closure designs work. It may be of value to study old natural formations, known to have been stable for long periods of time, as well in order to find out what has made them stable. The question is then how to achieve the same function for a man made tailings dam.

Sustainable closure design aims for walk away solutions, but, it is today difficult to know if that is achievable. As a result we need to provide for long-term responsibility, monitoring and maintenance, etc.

\section{Acknowledgement}

Thanks are due to the ICOLD committee on Tailings Dams and the Swedish subcommittee for supporting me to write and present this paper as a representative for them. Thanks also to Hugh Jones and Rob Williamson personally due to their great support and reviews of this paper.

The members of the Committee on Tailings Dams and Waste Lagoons: chairman: J.R.G. Williamson, South Africa; vice-chairman: J. Pimenta de Avila, Brazil. Members: J. Phillips, Australia; C.B. Abadjiev, Bulgaria; H. McLeod, Canada; G. Noguera, Chile; H. Xin, China; A. Marulanda, Colombia; K. Kast, Germany; V.K. Gupta, India; M. Askari, Iran; W. Wolski, Poland; E. Luca, Romania; A. Galperin, Russia; J.L. Justo, Spain; A.G. Bjelkevik, Sweden; M. Cambridge, UK; J.L.M. Clemente, US.

\section{References}

ICMM (2008) International Council on Mining and Metals. Planning for Integrated Mine Closure: Toolkit, London, UK, viewed 15 April 2011, http://www.icmm.com/library.

ICOLD Bulletin (in press) International Commission on Large Dams, Sustainable Design and Post-Closure Performance of Tailings Dams, http://www.icold-cigb.net/listepublications.aspx.

IISD (2002) International Institute for Sustainable Development. Seven Questions to Sustainability: How to Assess the Contribution of Mining and Mineral Activities, viewed 15 April 2011, http://www.iisd.org/pdf/2002/mmsd_ sevenquestions.pdf (2010-06).

UNWCED (1987) The World Commission on Environment and Development, Our Common Future, G. Bruntland (ed), Oxford: Oxford University Press, p. 43.

World Bank and IFC (2002) It's Not Over When It's Over: Mine Closure Around The World, Mining and Development Series, World Bank and International Finance Corporation, Washington, USA, viewed 04 April 2011, http://siteresources.worldbank.org/INTOGMC/Resources/notoverwhenover.pdf. 
